\title{
The role of chaplains in end-of-life decision making: Results of a pilot survey
}

\author{
STEPHANIE CLEMM, ${ }^{1}$ RALF J. JOX, MD, PHD, ${ }^{1,2}$ GIAN DOMENICO BORASIO, MD ${ }^{3}$ AND \\ TRAUGOTT ROSER, THD ${ }^{1,4}$ \\ ${ }^{1}$ Interdisciplinary Center for Palliative Medicine, Munich University Hospital, Munich, Germany \\ ${ }^{2}$ Institute for Ethics, History and Theory of Medicine, Munich University Hospital, Munich, Germany \\ ${ }^{3}$ Service de Soins Palliatifs, University of Lausanne, Lausanne, Switzerland \\ ${ }^{4}$ Department for Protestant Theology, University Münster, Münster, Germany \\ (RECEIVED November 25, 2012; ACCEPTED January 13, 2013)
}

\begin{abstract}
Objective: The overall aim of this study was to discover how chaplains assess their role within ethically complex end-of-life decisions.

Methods: A questionnaire was sent to 256 chaplains working for German health care institutions. Questions about their role and satisfaction as well as demographic data were collected, which included information about the chaplains' integration within multiprofessional teams.

Results: The response rate was 59\%, 141 questionnaires were analyzed. Respondents reported being confronted with decisions concerning the limitation of life-sustaining treatment on average two to three times per month. Nearly $74 \%$ were satisfied with the decisions made within these situations. However, only $48 \%$ were satisfied with the communication process. Whenever chaplains were integrated within a multi-professional team there was a significantly higher satisfaction with both: the decisions made $(p=0.000)$ and the communication process $(p=0.000)$.

Significance of the results: Although the results of this study show a relatively high satisfaction among surveyed chaplains with regard to the outcome of decisions, one of the major problems seems to reside in the communication process. A clear integration of chaplains within multiprofessional teams (such as palliative care teams) appears to increase the satisfaction with the communication in ethically critical situations.
\end{abstract}

KEYWORDS: Health care chaplaincy, End-of-life treatment decisions, Multi-professional treatment team, Palliative care

\section{INTRODUCTION}

Besides physical and psychosocial problems, the definition of palliative care by the World Health Organization also pays attention to spiritual issues (World Health Organization, 2012). It has been argued that spiritual care can be performed by all professionals working within palliative care (Frick et al., 2005). However, the integration of chaplains

Address correspondence and reprint requests to: Stephanie Clemm, Interdisciplinary Center for Palliative Medicine, Munich University Hospital, Professorship for Spiritualcare, Marchioninistraße 15, D-81377 Munich, Germany. E-mail: Steffi. clemm@web.de (or any professionals specialized in spiritual care) can be an enormous contribution to multi-professional teams in palliative care and in health care in general (Puchalski \& Ferrell, 2010).

Health care chaplains are frequently involved and often consulted in ethically complex issues and treatment decisions (Carey \& Cohen, 2008). Within a number of countries (e.g., Australia, UK, and USA) they are often included as members of hospital ethics committees (Carey, 2012a). In Germany, the protestant churches were the first to demand ethics support services in hospitals (Deutscher Evangelischer Krankenhausverband, 1997). The guideline of the Federal Chamber of Physicians in Germany explicitly recommends the presence of chaplains in ethics 
committees (Stellungnahme zur Ethikberatung in der klinischen Medizin, 2006). One of the most common issues of clinical ethics consultation is treatment limitation at the end-of-life (Fletcher, 1989; Vollmann, Burchardi \& Weidtmann, 2004).

The involvement of chaplains in end-of-life decision making is, however, not unchallenged. On the one hand, their recommendations are highly valued and most chaplains welcome their involvement in these issues (Carey \& Cohen, 2010). On the other hand, their presence is criticized due to their lack of ethical expertise, or respectively they play a less active role in ethics committees than the other professionals do (Kuhse \& Singer, 1985; McNeill, Berglund \& Webster, 1994). One of the great assets of chaplains, however seems to be their communication skills. They can frequently be involved in initiating communication to consider the patient's and/or the family's perspective with issues such as withdrawal of life support and not-for-resuscitation requests (McDaniel, 1999; Carey \& Newell, 2007a; 2007b).

However, it remains unclear how chaplains learn the specific ethical skills needed for end-of-life treatment decisions. Despite the fact that a basic understanding of ethics is part of theological studies, this is not a specific area within a chaplain's professional training. Clinical Pastoral Education in Germany does not include specific bioethical decision making as part of the training (Deutsche Gesellschaft für Pastoralpsychologie, 2006). International minimal educational standards for chaplains do not contain specific training in ethics/bioethics (Carey, 2012b).

There is almost no empirical data in Europe about chaplains' involvement in end-of-life treatment decisions.

This study aims to assess, in the German context, (1) how often chaplains are confronted with end-oflife treatment decisions, (2) how they judge their own confidence in this respect, (3) how they perceive their role within these decision making processes, and (4) how the integration within different teams influences these items.

\section{METHODS}

\section{Design and Sample}

To gain an overview of the practices and experiences of chaplains in Germany, we conducted a postal questionnaire survey. We addressed a convenience sample of chaplains working in German health care institutions. Potential participants were recruited from the working group "Spiritual Care" in the German Society for Palliative Medicine and from the relevant church authorities responsible for chaplaincy (Roman-Catholic and Protestant denominations). To mirror the heterogeneous confessional landscape in Germany we chose diverse, representative regions: Bavaria as overly Catholic region; Württemberg as mixed Catholic, Protestant and Muslim population, and Berlin and its surrounding areas as a secularized region (Evangelische Kirche im Rheinland, 2010).

\section{Survey Instrument}

The questionnaire was constructed on the basis of a previous study among physicians and nursing staff working in German intensive care units (Jox et al., 2010).

The survey contained 27 items, consisting of both closed and open-ended questions, as well as demographic data. Demographic data included information on sex, age, and religious affiliation as well as data about professional training, duration of work experience, and specifications on one's working situation (e.g., assignment in palliative medicine or intensive care medicine, integration within multi-professional teams). Questions regarding professional practice were based on the chaplains' experience with end-oflife decision making. An explicit definition of limiting life-sustaining treatment (LST) based on German law, was given: "Limiting LST means that a certain lifesustaining medical treatment is no longer being enforced. In case LST has been previously induced it is no longer being continued." It took approximately 10 to 15 minutes to complete the questionnaire.

\section{Questionnaire Administration}

The questionnaire was sent out by mail. A cover letter explained the background, aim, and anonymity of the survey. To ensure anonymity, all information concerning the respondent was immediately cleared as soon as the response was received. To increase the response rate, a reminder was sent out to all the chaplains after six weeks. The respondents could send back the questionnaire by mail, e-mail or fax.

The study design and questionnaire were a modification from a previous study implemented among doctors and nurses at the Munich University Hospital (Jox et al., 2010). This study was approved by Munich University's hospital institutional review board. The distribution of the questionnaires took place after acceptance and approval of the questionnaire by the accordant church authorities and the head of the working group "Spiritual Care" in the German society for Palliative Medicine (meeting in Saarbrücken, Germany, September 9, 2011).

\section{Quantitative Analysis}

SPSS for Windows (SPSS Inc., Chicago, IL), version 19.0 was used for data collection and statistical 
analysis. The frequency of limiting LST, reported per week, month or year was recalculated in frequency per year. Questions on the level of confidence, the quality of professional training, and the level of satisfaction with the decision and communication process, which could be answered in a balanced forced-choice four-item scale (i.e., "very certain", "rather certain", "rather uncertain", "very uncertain"), were dichotomized (e.g., "certain" and "uncertain"). To explore coherence between dichotomous variables, the Chisquare-test was calculated. In order to test coherence on scaled variables, a non-parametric test was applied: for two groups, the Mann-Whitney-U-test was implemented. Furthermore, the Kendall-Tau-b coefficient was calculated for ordinal variables, followed by a two-tailed test on significance. $P \leq 0.05$ was set as the level of significance.

\section{RESULTS}

The survey was mailed to 256 chaplains. Of the 151 returned questionnaires (response rate: 59\%), 141 (55\%) were analyzable. In the remaining 10 questionnaires demographic data was missing. The respondents' demographic data is presented in Table 1 .
The participants were requested to specify the degree of integration in their team. Regular involvement in meetings, such as team rounds and supervision meetings served as the basis for defining the degree of integration. Most respondents were integrated in Pastoral care teams $(n=105,75 \%)$, multi-professional treatment teams $(n=88,62 \%)$, and ethics support teams (ethics committees, $n=73,52 \%$ ). Some were also part of the hospital administration $(n=36,26 \%)$. The median number of confrontation with limiting LST was 18 times per year (mean = $28, S D=28$ ). Chaplains who were members of a multi-professional team, an ethics support team, or a palliative care team reported significantly higher rates of confrontation than the others (see Table 2).

Two-thirds of the chaplains indicated that they feel confident discussing the limitation of life-sustaining treatment $(n=94,67 \%)$. More than half of the respondents $(n=77,55 \%)$ felt that they had been well-prepared for these situations in their respective professional training. Explanatory notes suggested a lack of practical training in academic studies. Practical experience and continuous education were appreciated for including end-oflife decisions. If the chaplains were members of

Table 1. Respondents' demographic data $(\mathrm{n}=141)$

\begin{tabular}{|c|c|c|}
\hline & & $n(\%)$ \\
\hline \multirow[t]{2}{*}{ Sex } & Female: & $67(48)^{\mathrm{a}}$ \\
\hline & Male: & $74(53)$ \\
\hline \multirow{5}{*}{ Age (in years) } & $31-40$ & $6(4)$ \\
\hline & $41-50$ & $51(36)$ \\
\hline & $51-60$ & $62(44)$ \\
\hline & $61-70$ & $17(12)$ \\
\hline & $>71$ & $5(4)$ \\
\hline \multirow[t]{4}{*}{ Religious affiliation } & Protestant & $85(60)$ \\
\hline & Roman-Catholic & $47(33)$ \\
\hline & Non-denominational Christians & $9(6)$ \\
\hline & Non-Christians & $0(0)$ \\
\hline \multirow[t]{5}{*}{ Professional training ${ }^{b}$} & Clinical pastoral training ${ }^{\mathrm{c}}$ & $126(89)$ \\
\hline & Theological/religious-educational studies & $121(86)$ \\
\hline & Two-year internship/practical training phase & $50(36)$ \\
\hline & Palliative care course for chaplains ( $>120 \mathrm{~h})$ & $40(28)$ \\
\hline & Others & $54(38)$ \\
\hline \multirow[t]{4}{*}{ Field of work } & Hospital work & $105(75)$ \\
\hline & Nursing home care & $12(9)$ \\
\hline & Parish work & $5(4)$ \\
\hline & Combinations of the above named & $19(14)$ \\
\hline \multirow{2}{*}{ Specific medical environment } & Palliative care & $96(68)$ \\
\hline & Intensive care & $95(67)$ \\
\hline Duration of work experience (in years) & $>9$ & $79(56)$ \\
\hline in palliative care & $>5$ & $44(31)$ \\
\hline in intensive care & $>5$ & $67(48)$ \\
\hline
\end{tabular}

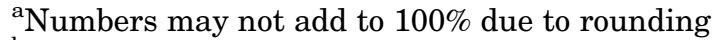

${ }^{\mathrm{b}}$ Multiple choices were possible

${ }^{\mathrm{c}} \mathrm{CPT} / \mathrm{CPE} /$ comparable pastoral-psychological qualifications
} 
Table 2. Reported frequency of confrontation with limiting $L S T^{\mathrm{a}}$ per year

\begin{tabular}{|c|c|c|c|c|}
\hline & & & Median & $\mathrm{SD}$ \\
\hline \multicolumn{5}{|l|}{ Specific medical environment } \\
\hline \multirow[t]{2}{*}{ Palliative care } & yes $]$ & $* * *$ & 24 & 32 \\
\hline & no & & 12 & 12 \\
\hline \multirow{2}{*}{ Intensive care } & yes & & 18 & 31 \\
\hline & no & & 18 & 23 \\
\hline \multicolumn{5}{|l|}{ Integration into } \\
\hline \multirow[t]{2}{*}{ Pastoral care team } & yes & & 18 & 26 \\
\hline & no & & 24 & 34 \\
\hline \multirow[t]{2}{*}{ Multi-professional team } & yes & $* * *$ & 24 & 32 \\
\hline & no & & 12 & 15 \\
\hline \multirow[t]{2}{*}{ Ethics support team } & yes & $* *$ & 24 & 28 \\
\hline & no & & 12 & 29 \\
\hline \multirow{2}{*}{$\begin{array}{l}\text { Hospital administration } \\
\text { team }\end{array}$} & yes & & 18 & 35 \\
\hline & no & & 21 & 26 \\
\hline
\end{tabular}

${ }^{a} \mathrm{LST}=$ life-sustaining treatment

$* * P \leq 0.01$ (Mann-Whitney-U-Test)

$* * * P \leq 0.001$ (Mann-Whitney-U-Test)

multi-professional teams, they felt significantly more confident in such situations (see Table 3 ). Statements regarding the quality of their professional training correlated positively with the level of confidence in end-of-life decisions $(r=0.24, p \leq 0.01)$. Furthermore, nearly all chaplains reported that the survey questions were highly relevant to them $(n=138$, 98\%) and stressed their strong desire for information $(n=135,96 \%)$.

More than half of the respondents $(n=73,52 \%)$ declared that end-of-life decisions were made cooperatively by the team of physicians; $42 \%(n=59)$ reported that the attending physicians made unilateral decisions. With regard to the involvement of other professionals in these decision-making processes, the following results were found: patient's family: $n=99,70 \%$; nursing staff: $n=64,45 \%$; spiritual care: $n=54,38 \%$. Chaplains who consider themselves members of a multi-professional team declared significantly more often that a patient's family, nursing staff, or chaplains were actively involved in the decision-making process (see Table 4).

All in all, three-quarters of the respondents reported being satisfied with end-of-life decisions $(n=104$, $74 \%)$. However, only half of the chaplains $(n=68$, $48 \%$ ) were satisfied with the communication process; these data were positively correlated $(r=0.61, p \leq$ 0.01). Professional experience and satisfaction with end-of-life communication were significantly inversely correlated $(r=-0.21, p \leq 0.01)$. Due to the lack of satisfaction regarding communicative structures, there remains a strong desire for supportive measures (see Fig. 1).

The role in which the chaplains see themselves in decision-making processes is most often as the patient's advocate $(n=91,65 \%)$ and the advocate of the patient's family $(n=81,57 \%)$. Less than half of the chaplains see themselves as members of the treatment team $(n=65,46 \%)$, consultant in theological-ethics $(n=62,44 \%)$, moderator $(n=50,36 \%)$, or church representative $(n=9,6 \%$; Fig. 2$)$.

\section{DISCUSSION}

The survey had a 59\% response rate, and can thus be considered to be sufficiently representative within the chosen sample (Asch, Jedrziewski \& Christakis,

Table 3. Reported levels of confidence, preparation and need for information $(n=141)$.

\begin{tabular}{|c|c|c|c|c|}
\hline & \multicolumn{4}{|c|}{ Integration into $^{a}$} \\
\hline & $\begin{array}{l}\text { Pastoral care } \\
\text { team, } n(\%)\end{array}$ & $\begin{array}{c}\text { Multi-professional } \\
\text { team, } n(\%)\end{array}$ & $\begin{array}{l}\text { Ethics support } \\
\text { team, } n(\%)\end{array}$ & $\begin{array}{c}\text { Hospital } \\
\text { administration } \\
\text { team, } n(\%)\end{array}$ \\
\hline I feel confident about limiting LST $^{\mathrm{b}, \mathrm{c}}$ & $73(72)$ & $65(76)^{*}$ & $51(72)$ & $27(77)$ \\
\hline $\begin{array}{l}\text { I feel well prepared by my professional } \\
\text { training for the decision to limit LST }\end{array}$ & $60(61)$ & $45(55)$ & $39(57)$ & $20(59)$ \\
\hline $\begin{array}{l}\text { I have a strong need for information on } \\
\text { the topic }^{d}\end{array}$ & $101(97)$ & $86(99)$ & $73(100)$ & $36(100)$ \\
\hline I think that the topic is important $\mathrm{e}^{\mathrm{e}}$ & $103(100)$ & $87(100)$ & $72(100)$ & $36(100)$ \\
\hline
\end{tabular}

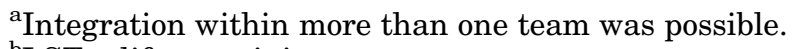

${ }^{\mathrm{b}} \mathrm{LST}=$ life-sustaining treatment.

"Sum of "very certain" and "rather certain."

"Sum of "very strong need" and "strong need."

"Sum of "very important" and "rather important."

$* p \leq 0.05$ (Chi-square-test).

Chi-square-test compares differences between being integrated and not being integrated in a special team.

The percentages are the result of the number of respondents who have explicitly answered the particular question. 
Table 4. Reported experience with end-of-life decision making $(n=141)$

\begin{tabular}{lcccc}
\hline \hline & \multicolumn{2}{c}{ Integration into $^{\mathrm{b}}$} \\
\cline { 2 - 5 } & $\begin{array}{c}\text { Pastoral care } \\
\text { team, } n(\%)\end{array}$ & $\begin{array}{c}\text { Multi-professional } \\
\text { team, } n(\%)\end{array}$ & $\begin{array}{c}\text { Ethics support } \\
\text { team, } n(\%)\end{array}$ & $\begin{array}{c}\text { Hospital administration } \\
\text { team, } n(\%)\end{array}$ \\
\hline $\begin{array}{l}\text { I am satisfied with the decisions } \\
\text { I am satisfied with the }\end{array}$ & $77(77)$ & $75(88)^{* * *}$ & $57(83)$ & $30(86)$ \\
$\begin{array}{c}\text { communication } \\
\text { Patient's family is involved in } \\
\text { decision-making process. }\end{array}$ & $51(51)$ & $54(63)^{* * *}$ & $38(54)$ & $21(60)$ \\
$\begin{array}{c}\text { Nursing staff is involved in } \\
\text { decision-making process. }\end{array}$ & $46(72)$ & $68(77)^{*}$ & $55(75)$ & $24(78)$ \\
$\begin{array}{c}\text { Chaplaincy is involved in } \\
\text { decision-making process. }\end{array}$ & $39(37)$ & $51(58)^{* * *}$ & $38(52)$ & $21(58)^{* * *}$ \\
\hline \hline
\end{tabular}

asum of "very satisfied" and "rather satisfied."

bIntegration within more than one team was possible.

$* p \leq 0.05$ (Chi-square-test).

$* * p \leq 0.01$ (Chi-square-test).

$* * * p \leq 0.001$ (Chi-square-test).

Chi-square-test compares differences between being integrated and not being integrated in a special team.

The percentages are the result of the number of respondents who have explicitly answered the particular question.

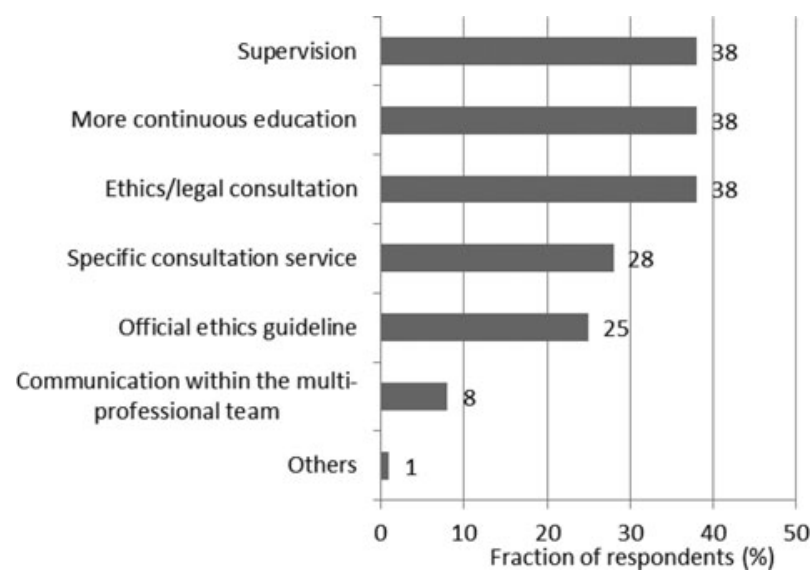

Fig. 1. Reported desire for supportive mesaures. Multiple choices were possible.

1997). The chaplains explicitly expressed the fact that these topics are of great importance to them. This is a remarkable result, since end-of-life decisions and the corresponding ethical conflicts are not necessarily topics that pertain directly to spiritual care (Deutsche Gesellschaft für Pastoralpsychologie, 2006; Carey, 2012b).

The interest shown by the chaplains may be due to the fact that they are confronted with end-of-life decisions on a regular basis (median $=18$ times per year). This data corresponds with data from Australian chaplains, where a large fraction $(57 \%$ of the staff chaplains and $28 \%$ of the volunteer chaplains) indicated to be involved with end-of-life decisions with patients or their families; $37 \%$ of the staff chaplains and $16 \%$ of the volunteer chaplains had

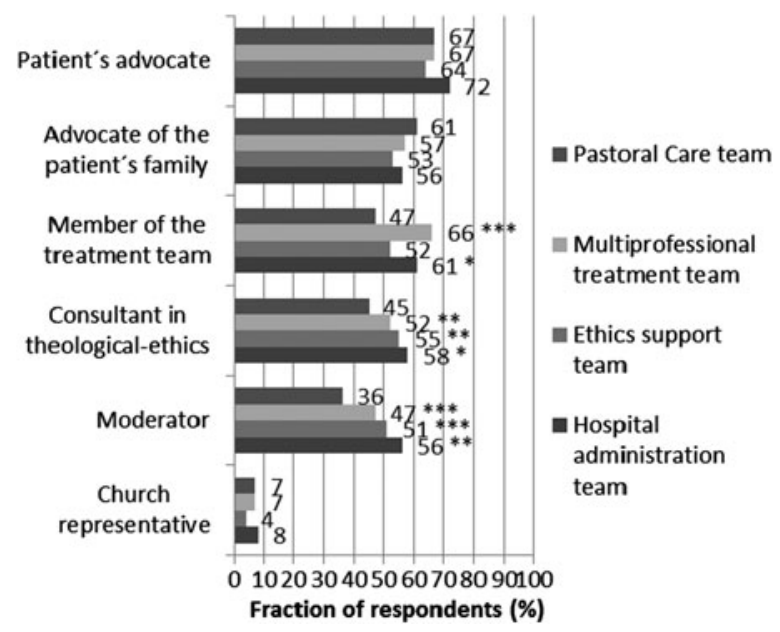

Fig. 2. The self-perceived role of chaplains within decisions concerning limiting of life-sustaining treatment. The histogram shows the answers of the respondents on their self-perceived role in dependence on their integration within different teams. Integration within more than one team was possible. The asterisks indicate significant differences between being integrated within a special team or not being integrated $(* p \leq 0.05, * * p \leq 0.01$, ***p $\leq$ 0.001 , Chi-square-test). The percentages are the result of the number of respondents who have explicitly answered the particular question (valid percentages).

assisted the clinical staff within these decisions (Carey \& Newell, 2007b). Remarkably, chaplains appear to be confronted with these decisions almost as often as senior physicians and nurses in German intensive care units (Jox et al., 2010). Chaplains who are a part of a palliative care team, an ethics support team, or a multi-professional treatment team, are confronted with these decisions significantly more 
often than chaplains who are not. This can be explained by the fact that in Germany chaplains are usually only regarded as members of the treatment teams in the context of palliative care. This is a result of the required multi-disciplinary approach in palliative medicine, as outlined by its WHO definition (World Health Organization, 2012). Caring for nonpalliative patients mainly involves physicians and care nurses, whereas chaplains are usually only involved in these cases if there is a specific need for them or due to a patient's explicit demand.

Notably, $67 \%$ of chaplains indicated that they felt confident with regard to end-of-life decisions. Again, chaplains who were part of a multi-professional team were more confident than those who were not. This may be due to the fact that in multi-disciplinary teams sharing responsibility is a basic principle. It would be interesting to figure out whether the level of confidence of other professionals is inversely increased if chaplains are members of the treatment team. The percentage of chaplains that indicated confidence in their end-of-life treatment decisions was significantly higher than that of a survey of physicians and care personnel in German intensive care units (Jox et al., 2010). Correspondingly, in the ETHICUS study, $81 \%$ of the respondent physicians in central Europe indicated that they did not have difficulties making end-of life treatment decisions (Sprung et al., 2008). The above mentioned survey among German intensive care unit staff showed a clear connection between insecurity with regard to end-of-life decisions and the amount of work/medical experience. The ETHICUS study, as well as the present study, surveyed mainly experienced professionals.

Importantly, the percentage of chaplains who feel well prepared for end-of-life situations through their professional training is lower (55\%). Indeed, end-oflife care and support and the corresponding ethical conflicts are not explicitly addressed within a chaplain's professional training curriculum in Germany (Deutsche Gesellschaft für Pastoralpsychologie, 2006). Many respondents reported to have absolved additional professional training in this area, which may contribute to the overall confidence concerning end-of-life decisions.

Despite the high degree of satisfaction among chaplains with end-of-life treatment decisions (74\%), the level of satisfaction with communication processes is significantly lower (48\%). Accordingly, supervision, which also serves the purpose of improving communicative competence, is one of the measures of support that was mentioned most frequently (Skinner et al., 2005). Official guidelines, which have a long tradition in the medical context, played a secondary role (Burns et al., 2003). Overall, our data show that being part of a multi-professional team has a positive effect on the level of satisfaction with the communication processes as well as with end-of-life decisions. Members of these teams indicated significantly more frequently that professionals other than the treating physicians (e.g., nurses, chaplains), were involved in the decision process.

The chaplains' self-perceived role in the context of end-of-life decisions seems to be primarily that of the patient's advocate, a role that is gaining importance within health care institutions (Mallik, 1997). Interestingly, chaplains who are involved as members in multi-professional teams see themselves significantly more often as a facilitator (i.e., facilitators of the communication process).

Our study has several limitations. It is not an objective evaluation of current practice, rather a subjective investigation based on the self-perspective of chaplains working in health care facilities. The study only looked at a limited sample, which may be biased with regard to membership in the German Society for Palliative Medicine. In addition, as with all questionnaire surveys asking for subjective parameters such as satisfaction with one's own practice, social desirability bias is possible.

\section{CONCLUSIONS}

This study provides first indications concerning the frequency and type of involvement of chaplains in end-of-life treatment decisions within a German cultural context. This evaluation will have to be followed up by investigations of these aspects amongst other professional groups, as well as in patients and relatives, as has already been done in other cultural and medical contexts (VandeCreek, 2004). End-of-life treatment decisions are known to be highly dependent on the religious and denominational backgrounds of all those involved (Sprung et al., 2003; Seal, 2010). Therefore, further studies of this topic in other cultural settings appear warranted.

\section{ACKNOWLEDGMENTS}

The authors are grateful for the participation of the respondents, for support of the church authorities responsible for chaplaincy and the working group 'Spiritual care' of the German Society of Palliative Medicine. Thanks are due to Dorothee Wagner von Hoff for language support. The authors are also grateful for creative ideas and critical appraisal of the study by all members of the Palliative Care research group Munich.

\section{REFERENCES}

Asch, D.A., Jedrziewski, M.K. \& Christakis, N.A. (1997). Response rates to mail surveys published in medical 
journals. Journal of Clinical Epidemiology, 50, 1129-1136.

Burns, J.P., Edwards, J., Johnson, J., et al. (2003). Do-notresuscitate order after 25 years. Critical Care Medicine, $31,1543-1550$.

Carey, L.B. \& Newell, C.J. (2007a). Chaplaincy and resuscitation. (European Journal) Resuscitation, 75, 12-22.

Carey, L.B. \& Newell, C.J. (2007b). Withdrawal of life support and chaplaincy in Australia. Critical Care and Resuscitation, 9, 34-39.

Carey, L.B. \& Cohen, J. (2008). Religion, spirituality and health care treatment decisions: The role of chaplains in the Australian clinical context. Journal of Health Care Chaplaincy, 15, 25-39.

Carey, L.B. \& Cohen, J. (2010). Health care chaplains and their role on institutional ethics committees: An Australia study. Journal of Religion and Health, 49, $221-232$.

Carey, L.B. (2012a). Bioethical issues and healthcare chaplaincy in Aotearoa New Zealand. Journal of Religion and Health, 51, 323-35.

Carey, L.B. (2012b). The utility and commissioning of chaplains, In The Textbook of Spirituality in Healthcare, Cobb, M., Puchalski, C. \& Rumbold, B. pp. 397-408. Oxford: Oxford University Press.

Deutscher Evangelischer Krankenhausverband, Katholischer Krankenhausverband Deutschlands (1997). EthikKomitee im Krankenhaus (Association of Protestant hospitals, Association of Catholic hospitals in Germany (1997). Hospital Ethics-committees). http://www. ev-medizinethik.de/pages/themen/gesundheitswesen und_ethikberatung/themenfelder/klinische_ethikkomit ees/index.html (Accessed on April 7, 2012).

Deutsche Gesellschaft für Pastoralpsychologie (2006). Sektion KSA Standards (German society for pastoral psychology (2006). Standards for clinical pastoral education). http://www.pastoralpsychologie.de/uploads/media/KSAStandards_2006.pdf (Accessed January 23, 2013).

Evangelische Kirche im Rheinland - Statistischer Dienst im Landeskirchenamt (2010). Statistik zur Synode 2010 (Protestant church in the Rhineland - Statistical service at the national church agency (2010). Statistics for the synod 2010). http://www.ekir.de/ekir/dokumente/Tab01.pdf (Accessed February 11, 2012).

Fletcher, J.C. (1989). Decisions to forego life-sustaining treatment. Virginia Medical Quarterly, 116, 462-465.

Frick, E., Riedner, C., Fegg, M.J., et al. (2005). A clinical interview assessing cancer patients' spiritual needs and preferences. European Journal of Cancer Care, 15, $238-243$.

Jox, R.J., Krebs, M., Fegg, M., et al. (2010). Limiting life sustaining treatment in German intensive care units: A multiprofessional survey. Journal of Critical Care, $25,413-419$.
Kuhse, H. \& Singer, P. (1985). Should the Baby Live? The Problem of Handicapped Infants. Oxford: Oxford University Press.

Mallik, M. (1997). Patient representatives: A new role in patient advocacy. British Journal of nursing, 6(2), $108-113$

McDaniel, C. (1999). Clergy contributions to health care ethics committees. HEC Forum, 11, 140-154.

McNeill, P.M., Berglund, C.A. \& Webster, I.W. (1994). Ethics at the borders of medical research: How much influence do various members have within research ethics committees? Cambridge Quarterly of Healthcare Ethics, 3, 522-532.

Puchalski, C.M. \& Ferrell, B. (2010). Making Health Care Whole - Integrating Spirituality into Patient Care. West Conshohocken: Templeton Press.

Seal, C. (2010). The role of doctors' religious faith and ethnicity in taking ethically controversial decisions during end-of-life care. Journal of Medical Ethics, 36, $677-682$.

Sprung, C.L., Cohen, S.L., Sjokvist, P., et al. (2003). End-oflife practices in European intensive care units. The ETHICUS study. Journal of the American Medical Association, 290, 790-797.

Sprung, C.L., Woodcock, T., Sjokvist, P., et al. (2008). Reasons, considerations, difficulties and documentation of end-of-life decisions in European intensive care units: The ETHICUS study. Intensive Care Medicine, 34, 271-277.

Skinner, N., Roche, A.M., O'Connor, J., et al. (2005). Workforce development 'TIP'. Clinical supervision. http:// www.unodc.org/ddt-training/treatment/VOLUME\% 20D/Topic\%202/8. Workforce\%20Development\%20TI PS.pdf (Accessed on April 25, 2012).

Stellungnahme der Zentralen Kommission zur Wahrung ethischer Grundsätze in der Medizin und ihren Grenzgebieten (Zentrale Ethikkommission) bei der Bundesärztekammer zur Ethikberatung in der klinischen Medizin (Statement of the central commission to uphold ethical standards in medicine (central ethics-commission) at the German medical association on ethics consults in clinical medicine). (2006). Deutsches Ärzteblatt, 103, A1703-A1707.

VandeCreek, L. (2004). How satisfied are patients with the ministry of chaplains? The Journal of Pastoral Care \& Counseling, 58, 335-342.

Vollmann, J., Burchardi, N. \& Weidtmann, A. (2004). Health care ethics committees in German university clinics. A survey of all medical directors and directors of nursing. Deutsche Medizinische Wochenschrift, 129, 1237-1242.

World Health Organization (2012). Definition of palliative care, http://www.who.int/cancer/palliative/definition/ en/ (Accessed on February 12, 2012). 